\title{
SAGRADO NÃO-BINÁRIO? O CONCEITO DE PSIQUE ANDRÓGINA NA REFORMULAÇÃO DO DEBATE DE GÊNERO NO SAGRADO FEMININO
}

\author{
Clarissa De Franco* \\ Eduardo Meinberg de Albuquerque Maranhão $\mathrm{F}^{\text {o**}}$
}

\begin{abstract}
RESUMO
O foco desse artigo é o debate de gênero, com possibilidades conciliatórias entre os Estudos de Gênero e a Psicologia Analítica. Utilizamos como campo o Sagrado Feminino e suas tensões conceituais sobre o ser mulher diante de algumas propostas feministas, já que os círculos sagrados de mulheres se apoiam na perspectiva dos arquétipos, animus e anima e têm utilizado tais conceitos de modo a reforçar o aspecto essencialista sobre o feminino. Embora as concepções iniciais de Jung sobre o tema reflitam sua época, uma leitura atenta de sua obra e de pós-junguianxs leva-nos à compreensão de que sua proposta carrega uma subversão das polaridades de gênero. Com a teoria de integração de polaridades e o politeísmo psíquico, os conceitos de animus e anima ganham uma perspectiva que foge ao dualismo binário e caminha para a androginia e não-binariedade de gênero. Palavras-chave: Gênero e Psicologia Analítica, Animus e Anima, Sagrado Feminino, Psique Andrógina, Sagrado Não-Binário.
\end{abstract}

* Psicóloga. Atua na Universidade Federal do ABC com Gênero, Direitos Humanos, Saúde Mental e Acessibilidade. Doutora em Ciência da Religião, com Pós-Doutorado em Estudos de Gênero.

** Docente-visitante do Programa de Pós-Graduação em Direitos Humanos, Cidadania e Políticas Públicas da Universidade Federal da Paraíba (PPGDH/UFPB) e do Centro de Ciências Jurídicas da mesma universidade (CCJ/UFPB). Doutorado em História Social pela Universidade de São Paulo (USP) com Pós-Doutorados em Ciências das Religiões pela Universidade Federal da Paraíba (UFPB), no Programa Interdisciplinar em Ciências Humanas e em História pela Universidade Federal de Santa Catarina (UFSC).

Mandrágora, v.25, n. 2, 2019, p. 127-151 


\title{
NON-BINARY SACRED? THE CONCEPT OF ANDROGYNOUS PSYCHE IN THE REFORMULATION OF GENDER DEBATE IN THE SACRED FEMININE
}

\begin{abstract}
The focus of this article is the gender debate, with conciliatory possibilities between the paradigms of Gender Studies and Analytical and Psychology. We use as a field the Sacred Feminine and its conceptual tensions about being a woman in the face of feminist proposals, since the sacred circles of women are based on the archetype perspective and have used the concept in their experiences in order to reinforce the essentialist aspect about the feminine. Although Jung's initial conceptions of the theme reflects his time, a close reading of his work, and of post-junguians, leads us to the understanding that the proposition of analytic psychology has in its core a subversion of polarities of gender. With the theory of integration of polarities and psychic polytheism, the concepts of animus and anima gain a perspective that escapes binary dualism and moves toward androgyny and non gender binary. Keywords: Gender and Analytical Psychology, Animus and Anima, Sacred Feminine, Androgyne Psyche, Non-binary Sacred.
\end{abstract}

\section{¿SAGRADO NO BINARIO? EL CONCEPTO DE PSIQUE ANDRÓGINA EN LA REFORMULACIÓN DEL DEBATE DE GÉNERO EN EL SAGRADO FEMENINO}

\begin{abstract}
RESÚMEN
El enfoque de este artículo es el debate de género, con posibilidades conciliatorias entre los Estudios de género y la Psicología analítica. Usamos como campo lo Sagrado Femenino y sus tensiones conceptuales sobre ser una mujer frente la algunas propuestas feministas, ya que los círculos sagrados de las mujeres se basan en la perspectiva de los arquetipos, animus y anima y han usado tales conceptos para reforzar el aspecto esencialista sobre las mujeres. Aunque las concepciones iniciales de Jung sobre el tema reflejan su tiempo, una lectura cercana de su trabajo y post-Junguianxs nos lleva a comprender que su propuesta conlleva una subversión de las polaridades de género. Con la teoría de la integración de la polaridad y el politeísmo psíquico, los conceptos de animus y anima adquieren una perspectiva que cambia del dualismo binario a la androginia de género y no binario. Palabras-clave: Género e Psicología Analítica, Animus y Anima, Sagrado Femenino, Psique Andrógina, Sagrado No Binario.
\end{abstract}




\section{INTRODUÇÃO}

Ao buscar conciliar caminhos teóricos de matrizes distintas, é preciso ter um cuidado profundo para não apressar o estabelecimento de semelhanças conceituais de modo artificial - movimento cuidadoso que buscaremos realizar neste artigo. Este trabalho tem como objetivo e desafio mostrar que, embora o uso de conceitos da Psicologia Junguiana, como arquétipos, anima e animus, tem reforçado uma perspectiva reducionista, binária e essencialista de gênero dentro de movimentos como o Sagrado Feminino, tal perspectiva não corresponde à amplitude de possibilidades que as teorias analítica e arquetípica permitem. Nesse sentido, há nesse texto uma defesa de que tanto Jung quanto as teorias pós-junguianas são muito mais subversivas do que o uso que se tem feito delas, permitindo uma leitura plural e fluida de gênero que vai ao encontro da perspectiva dos Estudos de Gênero.

Respeitando as devidas matrizes de pensamento, abrimos diálogo entre a perspectiva de hibridismo ciborgue presente em feministas como Donna Haraway (2013) e as hipóteses andrógina e políteísta encontradas nas perspectivas de Jung, principalmente em seus escritos ligados à alquimia (Carl G. JUNG, 2002) e na perspectiva de James Hillman (1983; 1985) quando aposta na pluralidade de representações narrativas, simbólicas e imagéticas da alma e da psique e faz uma releitura do conceito de anima, abrindo possibilidades para uma compreensão fluida e multifacetada de gênero.

Os Estudos de Gênero, em geral, chamam atenção para a produção discursiva e normativa de dicotomias, nas quais a pluralidade e as nuances da subjetividade se perdem. Socialmente, categorias como homem, masculinidade, mulher, feminilidade, heterossexualidade, homossexualidade, cisgeneridade, transgeneridade, entre outras, acabam por enquadrar-se em constructos pré-concebidos. Os binarismos de gênero, para os quais várixs autorxs chamam atenção (Judith BUTLER, 2001; 2003, Londa SCHIENBINGER, 2000; Diana MAFFÍA, 2008; Donna HARAWAY, 2013), sustentam exclusões, invisibilizações e violências de gênero, na medida em que estabelecem artificialmente definições estáticas, pré-concebidas e fixas que tendem a naturalizar padrões, discursos e comportamentos ligados ao gênero e estabelecem hierarquias e desigualdades nas relações de gênero. 
A pesquisadora argentina de gênero Diana Maffía (2008, p. 2) mostra as duas colunas abaixo, indicando que uma coluna está associada a características comumente atribuídas ao feminino e outra ao masculino. Sem apontar qual coluna se refere a cada construto, ela sugere que automaticamente já atribuímos as características da esquerda ao universo dos homens e o da direita ao das mulheres - isso por conta de todo o processo de produção social de dicotomias, que tendem a reforçar os papeis e expectativas sociais binárias sobre o que é feminino e o que é masculino.

$\begin{array}{cc}\text { OBJETIVO } & \text { SUBJETIVO } \\ \text { UNIVERSAL } & \text { PARTICULAR } \\ \text { RACIONAL } & \text { EMOCIONAL } \\ \text { ABSTRACTO } & \text { CONCRETO } \\ \text { PÚBLICO } & \text { PRIVADO } \\ \text { HECHOS } & \text { VALORES } \\ \text { MENTE } & \text { CUERPO } \\ \text { LITERAL } & \text { METAFÓRICO }\end{array}$

No campo da Psicologia Analítica, cabe indicar, conforme apontam Polly Young-Eisendrath e Terense Dawson (2002), que as concepções iniciais de Jung sobre o masculino e o feminino refletiram sua época e acabaram por atribuir à feminilidade noções como subjetividade e intuição, e à masculinidade identificações com racionalidade, objetividade. Esse pensamento inicial de Jung em seus primeiros escritos, e as primeiras definições acerca de animus e anima, deram lugar ao entendimento de que essa teoria reforça os binarismos de gênero

Contudo, uma leitura atenta sobre a obra de Jung e de pós-junguianxs leva-nos à compreensão de que a proposta da Psicologia Analítica tem, em seu bojo, uma possível subversão das polaridades de gênero, conforme veremos.

Nosso texto começa apresentando o Sagrado Feminino e apontando alguns exemplos de como a feminilidade tem sido abordada em alguns desses círculos de mulheres, a partir da percepção que os mesmos costumam ter de conceitos junguianos. Depois, apresentamos como a Psicologia Analítica e Arquetípica podem se recolocar no debate de gênero. Na terceira etapa do texto, apresentamos as visões da psique andrógina e estabelecemos uma discussão com o conceito de 
ciborgue de Donna Haraway. Fechando este itinerário, apresentamos considerações finais, ainda que não pretendendo concluir o assunto.

\section{O SAGRADO FEMININO E OS PRINCÍPIOS CONCEITUAIS DE SUA ESPIRITUALIDADE}

A antropóloga Daniela Cordovil (2015), que analisou o Círculo de Mulheres Isis-Afrodite de espiritualidade Wicca em Belém do Pará, afirma que, com a chamada Nova Era, a humanidade passa a identificar a supremacia do masculino e a mentalidade patriarcal como "predadora do meio ambiente e dos demais grupos humanos" (p. 432), propondo um "resgate do feminino como elemento primordial da conexão com o sagrado" (p. 432). Em suas análises, que sugerem que o Sagrado Feminino começa a ganhar relevância junto com os movimentos feministas ocidentais de um modo geral, ela observa que a sacralidade da mulher nesse círculo da Wicca apoia-se nos "mistérios do feminino, como a menarca, a gravidez e a menopausa” (Daniela CORDOVIL, 2015, p. 432). Resgata-se uma conexão do corpo da mulher com os ciclos da natureza, em especial as estações do ano e as fases da lua.

Além de símbolos como a menstrução e a gravidez, o feminino é exaltado e reconhecido por características ligadas a figuras femininas que representam aprendizados para as mulheres. A página animacura. com. $b r^{1}$ assim descreve a feminilidade: "Essa energia está ligada à receptividade, passividade, criação, aceitação de si, aprofundamento do ser, construção de valores no lar da alma, multifuncionalismo e tantas outras coisas". O Instituto de Pesquisas e Tratamentos Humanísticos ${ }^{2}$ propõe, em um de seus textos, "[...] o reencontro da mulher com o aspecto sagrado da sua polaridade feminina".

Essas passagens ilustram uma visão do feminino como associada a algumas características determinadas (passividade, receptividade, alma, intuição, criação, subjetividade, profundidade, etc.) que, conforme sinalizamos na introdução deste texto, são pensamentos estereotípicos e dicotômicos, apontados pelos Estudos de Gênero, já aqui mencionados, como frutos de imaginários que reforçam as exclusões, desigualdades

Disponível em: <http://www.animacura.com.br/tag/sagrado-feminino/>. Acesso em agosto de 2019. Disponível em: <https://ipth.com.br/arquetipos-do-sagrado-feminino/>. Acesso em setembro de 2019. 
e invisibilidades de gênero e que colocam as mulheres atreladas a atributos socialmente menos valorizados.

Citamos outro exemplo de associação do feminino com alguns atributos, como a beleza. No trecho retirado de uma página na web (estudioflordelotus.com) que chama para uma vivência de Sagrado Feminino, assim se contextualiza:

A utilização das mitologias das deusas pode auxiliar as mulheres no processo de autoconhecimento porque os contos em torno das deusas foram criados a partir de atributos femininos, e da natureza, presentes em todas as mulheres. Por exemplo, com o mito da deusa Amaterasu, deusa do sol do Japão, que representa a beleza, podemos refletir sobre a possibilidade de estarmos presas a determinados padrões, e despertarmos para o brilho da nossa própria beleza interna ao invés de seguir padrões da sociedade... ${ }^{3}$

Percebemos, nesta perspectiva, que a beleza feminina divina é associada à beleza feminina humana - ainda que a autora do texto tenha sublinhado que a beleza exterior da deusa do sol nipônico possa se relacionar não necessariamente à beleza exterior das mulheres, mas à interior. De toda a maneira, a beleza física divina é atributo sublimemente relacionado à feminilidade de corpo e alma.

Avançando mais nas pesquisas de propostas e visões dos círculos de mulheres, percebemos que há um uso de alguns conceitos da teoria junguiana, juntamente com a perspectiva de apoio mitológico. A sacralidade do feminino e de seus ciclos aponta para uma busca de empoderamento e conscientização das mulheres sobre si mesmas, seus ciclos corporais, seu papel na história com figuras femininas de referência, as características que lhes (nos) seriam comuns e partilhadas. Nesse contexto, representações de distintas tradições mitológicas, religiosas, filosóficas e culturais, além de figuras históricas, são resgatadas e colocadas lado a lado, como forma de gerar referências femininas atemporais. Diana, Afrodite, Atena, Iemanjá, Mãe Terra, Lua, Deusa Tríplice, Joana

3 Trecho do texto não acadêmico: A Deusa, a dança e o Sagrado Feminino. Disponível em: <https://www.estudioflordelotus.com/2018/03/24/deusa-danca-e-o-sagrado-feminino/>. Acesso em setembro de 2019. 
Darc, entre outras mulheres históricas ou míticas que oferecem uma possibilidade de representação arquetípica.

A página todamulheresagrada.com cita o arquétipo da Grande Mãe, um conceito da teoria junguiana, para explicar sua prática:

Na Mitologia Grega, a energia feminina era reverenciada pela representação do arquétipo da Grande Mãe, que foi dividido em seis partes. Mais especificamente, em seis Deusas Gregas: Atena, Ártemis, Afrodite, Hera, Perséfone e Deméter. Cada Mulher possui essas Deusas em si, mas sempre há um ou dois arquétipos que nos identificamos mais, enquanto outros se manifestam pouco ou estão reprimidos. Há também momentos da nossa vida em que um deles está e precisa ser enaltecido. Em um mesmo dia, dependendo da situação, somos mais de uma Deusa. ${ }^{4}$

Um uso similar pode ser encontrado em várias páginas da web que abordam o Sagrado Feminino ${ }^{5}$ É claro que o nível de profundidade nessa abordagem varia entre os grupos e as facilitadoras, mas é preciso compreender que a matriz da sacralização do feminino nos círculos de mulheres associa a feminilidade ao corpo, à natureza, à possibilidade de gestar filhos, à menstruação e a características como receptividade, intuição, subjetividade, alma, beleza.

\section{A SAGRADA BINARIEDADE DOS CÍRCULOS DE SAGRADO FEMININO E A TRANSFOBIA ESPIRITUALISTA}

Preliminarmente podemos considerar: somente pessoas auto-designadas mulheres possuiriam tais arquétipos femininos ou pessoas que se identificam como homens, também? E em relação às pessoas andróginas? E quanto às pessoas não-binárias de gênero?

4 As Deusas gregas e seus arquétipos. Disponível em: <http://todamulheresagrada.com/as-deusas-gregas-e-seus-arquetipos/>. Acesso em setembro de 2019. A matéria tem asterisco na palavra arquétipos e traz uma legenda ao final: “*O conceito de arquétipos surgiu em 1919 com o psicólogo suíço Carl Gustav Jung. Segundo ele, os arquétipos são conjuntos de "imagens primordiais" originadas de uma repetição progressiva de uma mesma experiência durante muitas gerações, armazenadas no inconsciente coletivo".

5 Disponível em: <https://ipth.com.br/arquetipos-do-sagrado-feminino/>. Acesso em setembro de 2019. https://atitudescomexcelencia.com.br/2019/02/14/os-arquetipos-das-deusas-e-o-feminino/. Acesso em setembro de 2019. Disponível em: <http://www.ladybetwixt.com/2011/05/o-feminino-e-seus-arquetipos-as-sete.html>. Acesso em agosto de 2019. 
E quais são as mulheres autorizadas pelas deusas a se perceberem mulheres e participarem dos círculos sagrados de feminilidade? Seriam somente as mulheres cisgêneras ou também as transgênero? Mulheres transexuais e travestis poderiam reivindicar o título de mulheres e serem acolhidas em tais círculos?

O feminino transgênero, um feminino que transita, borra, desafia fronteiras do que é ser mulher e cruza fronteiras de gênero de modo mais amplo, coloca-se, diante da perspectiva do feminino sacralizado binarizado e naturalista dos círculos sagrados, como um desafio. Afinal, definir as mulheres a partir de características a elas historicamente atribuídas não seria justamente um reforço ao pensamento binário e dicotômico no qual se apoia o patriarcado e as invisibilidades e exclusões de gênero? A sacralidade do feminino estaria na vagina? Na menstruação? $\mathrm{Na}$ intuição? Na maternidade? E as mulheres que não menstruam, não têm filhxs, não têm vagina, não são intuitivas?

Como salientou Eduardo Meinberg de Albuquerque Maranhão $\mathrm{F}^{\circ}$, existe uma transfobia religiosa / espiritualista, "que pode ser definida como a aversão / discriminação / intolerância / violência a pessoas transgênero a partir de concepções, pressupostos e/ou dogmas religiosos ou espiritualistas" (Eduardo MARANHÃO Fo, 2014). Esta forma de transfobia, segundo estx autorx, se dá através de regimes de verdade e poder enunciados a partir do dispositivo da cisheteronormatividade e transparece em diversos âmbitos e de diversas formas, ultrapassando o cosmos católico e evangélico, como em igrejas do Santo Daime, no kardecismo, umbandaime, umbanda, xamanismo, wicca, e também, nos círculos de Sagrado Feminino e de Sagrado Masculino. Em breve pesquisa realizada por Maranhão $\mathrm{F}^{\circ}$ no círculo místico da ilha da magia (Florianópolis, Santa Catarina) entre 2016 e 2017, foram percebidos casos

[...] em que pessoas transgêneras em geral (a partir de auto-declarações como homem trans, mulher transexual, travesti e não-binárie, dentre outras) não eram aceitas - na integridade subjetiva de seu gênero" em círculos como estes, tendo como "justificativa" que "as pessoas eram entendidas como mulheres se tivessem estrutura física de mulheres, incluindo útero, por exemplo, e como homens caso tivessem "todo o aparato de homem". Pessoas não-binárias, de modo idêntico, deveriam ser encaixadas conforme seu "sexo de nascimento". (Eduardo MARANHÃO Fo, 2017, p. 204). 
Para Maranhão $\mathrm{F}^{\circ}$,

Tal biologização do corpo/sexo/gênero (por que não dizer também d'alma?) que pode ou não ser considerado feminino ou masculino (ou memo não-binárie) não leva a sério as sensibilidades e subjetividades de pessoas que não nasceram com o aparato físico esperado a quem é outorgado/a "homem" ou "mulher". No caso, por exemplo, de pessoas que se declaram mulheres trans e travestis e que não são aceitas em tais ambientes por não terem útero, ovários ou passarem por ciclos menstruais, ficam indagações: o que é ser mulher? É realmente algo referente ao biológico? Não é, afinal, uma questão política e sócio-culturall? quantas mulheres (assim designadas ao nascerem) não tem útero, ovários, seio(s)? por acaso deixam de serem consideradas mulheres? Afinal, para ser considerada mulher é necessário passar por ciclos menstruais? Creio que não: ser mulher é questão do subjetivo, não do biológico. (Eduardo MARANHÃO Fº 2017, p. 204).

Nesta perspectiva, condizente com a maioria dos estudos de gênero, gênero não é questão biológica, mas sócio-cultural, é algo edificado espaço-temporalmente de acordo com determinados contextos culturais.

$\mathrm{X}$ autorx contempla ainda que

De todo modo, e como mencionado, o assunto não deve ser considerado a partir de uma chave reducionista ou essencialista: a transfobia religiosa / espiritualista pode transparecer em um terreiro e não em outro, em uma filial de determinada igreja e não em outra filial, em um círculo sagrado e não no outro, em uma pessoa e não na outra, etc. Nos casos da não-aceitação de pessoas transgêneras, ficava patente o dispositivo da cisnormatividade binária, fundada na biologização (muitas vezes coligada a uma patologização/psiquiatrização/judicialização) destas e sem levar em conta suas emoções, sensibilidades e subjetividades (Eduardo MARANHÃO Fo, 2017, p. 204).

Assim, é muito possível que nem todos os círculos de Sagrado Feminino e de Sagrado Masculino pratiquem formas de transfobia mística l espiritualista com pessoas que visitem ou frequentem tais espaços e que não sejam outorgadas como mulheres cisgêneras.

De toda forma, continuando a comentar sobre um contexto geral de nossa pesquisa junto a círculos de Sagrado Feminino contemporâ- 
neos e situados no eixo Sul e Sudeste brasileiros entre 2015 e 2019, é possível refletir ainda que, se as mulheres participantes de círculos de Sagrado Feminino recebem as bençãos das deusas arquetípicas, elas são por elas autorizadas a perpetuarem a concepção de que mulheres são essencialmente diferentes de homens em relação a características culturais, emocionais e espirituais. Essa autorização da voz sagrada encontra ressonância em escritos de Pierre Bourdieu (1996) e de Eni Orlandi, quando esta última nota que no discurso religioso autoritário, "reformulando a definição que havia proposto, eu diria agora que no discurso religioso, em seu silêncio, "o homem faz falar a voz de Deus" (Eni ORLANDI, 2007, p. 28) - o que, em relação ao Sagrado, Feminino pode ser compreendido como: neste discurso místico / espiritualista, as mulheres fazem falar a voz das deusas arquetípicas, e essas vozes reforçam peremptoriamente a polaridade homem / mulher.

É possível, nesse trânsito não completamente realizado que pessoas transgênero (binárias e não-binárias) fazem pelos fiordes do Sagrado Feminino, que ao invés de sentirem-se empoderadas pelas deusas e pelas humanas, estas se sintam tão discriminadas e excluídas ao ponto de desenvolverem certa transfobia internalizada, quando a própria pessoa transgênero rejeita a si mesma por ser transgênero - algo recorrente em casos de missões católicas e evangélicas que pregam que homens e mulheres são criados/as por Deus e que os sinais da criação encontram-se no corpo (Eduardo MARANHÃO Fo, 2014, 2016, 2017).

\section{ENTRE O CIBORGUISMO E AS POSSÍVEIS RELAÇÕES COM A "IDEOLOGIA DE GÊNESIS"}

A feminista Donna Haraway afirma que prefere ser um ciborgue que uma deusa, já que "o ciborgue não é parte de qualquer narrativa que faça um apelo a um estado original" (Donna HARAWAY, 2013, p. 38). Seu Manifesto Ciborgue (2013) mostra como os hibridismos humano/ máquina estariam na base das transformações identitárias de gênero que desafiam um imaginário ideal normatizador das subjetividades.

Aqui insere-se o debate sobre natureza e cultura, palco de tantas tensões relativas ao campo de gênero. Boa parte destas tensões refletem uma tensão ainda maior entre religião e gênero, em que a natureza 
do corpo tem sido associada ao que o divino criou e as transformações culturais, ao que o ser humano deformou da criação (Maria José ROSADO-NUNES, 2015). Embora a espiritualidade New Age não se proponha a manter os mesmos padrões rígidos da religiosidade tradicional cristã - esta última associada a parâmetros patriarcais, nos quais as mulheres acabam por ocupar papeis submissos, secundários, identificados com uma condição idealizada e assexualizada (Maria, virgem, mãe casta), ou ainda voltada a parâmetros pecaminosos e demonizados, como os relacionados a Eva (Carolina LEMOS, 2013) -, quando o Sagrado Feminino mantém discursos que essencializam uma natureza da mulher, acaba por situar-se em um lugar desconfortável em relação às lutas de gênero.

Enquanto a(s) ciência(s) caminham na dissolução da antítese, numa trilha de conciliação entre natureza e cultura, entendendo que faz parte da natureza humana produzir cultura e parte da cultura humana produzir naturalizações que levam a percepções de que determinados conceitos seriam naturais e anteriores aos processos culturais - como o conceito de corpo, explicitado por Judith Butler (2001) como fruto de naturalização, já que o corpo também deriva de construções sociais -, os discursos religiosos cristãos que adentram o debate dos movimentos aqui estudados resgatam o vigor da fronteira e da dicotomia entre natureza e cultura, numa alusão à divisão entre perfeição e imperfeição, divindade e humanidade, em uma perspectiva dualista entre natureza e cultura, valorizando a natureza e patologizando ou demonizando o que vem da cultura como aberração, perversão, doença ou síndrome.

Nesse sentido, o Sagrado Feminino, que não se enquadra como uma religião tradicional, mas como uma espécie de movimento místico / espiritualista, acaba por não se distanciar de princípios reducionistas relacionados a gênero e que estão na base da tensão com as feministas políticas.

De alguma forma, o Sagrado Feminino acaba por tangenciar uma certa ideologia de gênesis que entende que Deus criou macho e fêmea, em que "crê-se que há somente dois sexos concebidos por Deus (masculino e feminino), devidamente hierarquizados a partir das ideias de que a mulher veio da costela do homem" (Gênesis 2:22; 1 Coríntios 11:9) 
e de que esse é "o cabeça da relação" (Efésios 5:23; 1 Coríntios 11:3)" (Eduardo MARANHÃO $\mathrm{F}^{\circ}$, 2018). ${ }^{6}$

No caso do Sagrado Feminino, de modo semelhante à ideologia de gênesis propagada por correntes católicas e evangélicas superconservadoras, as mulheres possuiriam - desde o início dos tempos e (in suposto) abençoadas pelas deusas arquetípicas - características fundamentalmente femininas e os homens, fundamentalmente masculinas (o que também é reproduzido em círculos de Sagrado Masculino).

Revigora-se, assim, que homens são de um jeito e mulheres de outro, ambxs enfeixadxs em fronteiras essencialistas e reducionistas de gênero que são determinantes, fixas e acabadas, desprivilegiando e apagando quaisquer possibilidades de borramento das fronteiras de gênero.

\section{REVENDO O PAPEL DA PSICOLOGIA ANALÍTICA E ARQUETÍPICA NO DEBATE DE GÊNERO}

Conforme observamos, o Sagrado Feminino, que enaltece deusas e figuras femininas mitológicas e históricas de referência, apoia-se epistemologicamente na perspectiva arquetípica, vinda da Psicologia Junguiana. Tal perspectiva considera que existem estruturas na psique humana que perpassam culturas e períodos históricos, que seriam como modelos que se configuram em imagens primordiais associadas a experiências da humanidade presentes no inconsciente coletivo. Estamos nos referindo aos arquétipos, conceito desenvolvido por Jung (2000).

Sempre que falamos de estruturas que perpassam xs humanxs de todas as épocas, as antenas de estudiosxs e militantes de gênero se erguem, afinal, o acultural e o atemporal são caminhos que facilmente desembocam em naturalizar o que poderia ser localizado histórica e socialmente. No entanto, Jung (2000) reforça que o arquétipo não se refere a um conteúdo fixo.

Nenhum arquétipo pode ser reduzido a uma simples fórmula. Trata-se de um recipiente que nunca podemos esvaziar, nem encher. Ele existe em si apenas potencialmente e quando toma forma em alguma

6 Sobre os recentes movimentos da ideologia de gênesis relacionada à política brasileira do tempo presente, sugerimos: MARANHÃO F', DE FRANCO, 2019. 
matéria, já não é mais o que era antes. Persiste através dos milênios e sempre exige novas interpretações. Os arquétipos são os elementos inabaláveis do inconsciente, mas mudam constantemente de forma. (JUNG, 2000, p. 179).

Em complemento, o autor afirma: "O arquétipo é um elemento vazio e formal em si [...] uma possibilidade dada a priori da forma da sua representação. O que é herdado não são as ideias, mas as formas, as quais sob esse aspecto particular correspondem aos instintos igualmente determinados por sua forma" (Carl JUNG, 2000, p. 91). Uma imagem arquetípica não é o arquétipo em si, sendo a imagem uma via de representação, observação e acesso ao arquétipo, que contém ou amplifica o símbolo. $O$ arquétipo em si não pode ser apreendido pela psique em sua totalidade.

Na Psicologia Arquetípica, cujo principal representante é James Hillman, o trabalho arquetípico ganha uma dimensão de ainda maior importância. Para Hillman (1983, p. 21), o "arquetípico pertence a toda a cultura, a todas as formas de atividade humana". Hillman era psicólogo junguiano e foi diretor do Instituto C. G. Jung de Zurique. Basicamente, na transição do pensamento analítico (da escola clássica) para o arquetípico, não houve ruptura com as bases do pensamento junguiano, mas ocorreu uma dissidência, que modifica alguns eixos conceituais. $\mathrm{O}$ primeiro ponto que destacamos é que a Psicologia Arquetípica centrase na exploração da imagem como forma de recriação dos caminhos de manifestação e representação do arquétipo.

A alma se torna central na Psicologia Arquetípica, que passa a exigir uma postura de rompimento com o controle ilusório do ego, reconhecendo que a alma é composta por uma pluralidade de arquétipos. As metáforas, os mitos, os sonhos, os processos da imaginação, as narrativas que as pessoas contam sobre si e para si, são a alma manifesta, e a psique pode ser reconhecida e reconduzida para a cura e transformação observando tais narrativas e ampliando as possibilidades e os significados simbólicos que as imagens e histórias apontam.

Nesse sentido, como a alma é rica de politeísmo, deuses, deusas, arquétipos, símbolos, imagens e narrativas, a exploração de novas e múltiplas possibilidades é o caminho da criação e recriação da alma. 
"A personalidade é imaginativamente concebida como um drama vivo e cheio de gente no qual o sujeito "Eu” toma parte, mas não é o único autor, nem o diretor, e nem sempre a personagem principal" (James HILLMAN, 1983, p. 89).

Hillman busca investigar "qual figura divina está falando nesse estilo de consciência” (James HILLMAN, 1983, p. 64). O movimento da Psicologia Arquetípica é evidenciar e visibilizar qual figura divina ou mítica está personificando e patologizando a psique, de modo a restabelecer seu fluxo energético.

Aplicando ao campo de gênero, Hillman afirma que "tomamos a anima personalisticamente" e que "enganamos o ego dessa forma", então "perdemos o significado mais amplo de anima" (James HILLMAN, 1983, p. 8). Gustavo Barcellos (In: Hames HILLMAN, 1983) sugere que com Hillman e a perspectiva da psicologia arquetípica, a psique e a alma podem se livrar de serem sempre pensadas em termos de opostos. "Podemos ver que anima, alma, está por tudo e em tudo, não só na interioridade feminina do homem. Está no homem e na mulher" (Gustavo BARCELLOS in James HILLMAN, 1983, p. 9).

Nesse sentido, a narrativa fala por si, conta os aspectos que estão bloqueados, os simbolismos que perderam sua elasticidade e fluidez. A enfermidade mora na estagnação, na impossibilidade de transformação que gera uma fantasia patológica. Voltar ao arquétipo original ligado à narrativa patológica é descobrir novos caminhos de ressignificação simbólica. À proposta de explorar as imagens até que se crie um novo significado, Hillman nomeou de "criação da alma" (1983). Ele sugere que a cura para as dores psíquicas reside na criação de novos significados para as imagens e narrativas que temos sobre nós mesmxs.

Nesse sentido, toda a concepção de gênero que dialogue com a Psicologia Analítica e a Psicologia Arquetípica deve partir de uma perspectiva de psique plural, fluida, dinâmica e que tem múltiplas facetas e possibilidades representativas. Consideramos que os conceitos de anima e animus, comumente associados a determinadas características do ser mulher e do ser homem ou à feminilidade e masculinidade, talvez estejam sendo usados de modo equivocado, em especial quando vinculam a temática de gênero a figuras estáticas. O uso popular da teoria 
arquetípica de Jung transformou a perspectiva dos arquétipos em uma matéria de direção unicamente essencialista, quando sua teoria aponta para outros parâmetros.

Roberto Novaes De Sá e Tatiana Deola (2019, p. 15) analisam: “Compreendemos que estas confusões são causadas pela personificação literal no entendimento da dinâmica psíquica relacionada ao princípio de complementariedade, ou seja, uma tentativa de objetivar tecnicamente a anima e o animus". Há que enxergar a personificação da anima e do animus por meio das imagens e figuras que se revelam, de modo a superá-las e transpô-las.

\section{CIBORGUISMO, ANDROGINIA E NÃO-BINARIEDADE}

Por mais que reconheçamos que as perspectivas iniciais de Jung apoiaram o reforço aos binarismos de gênero e podem ter dado espaço para as formulações personificadas sobre o feminino e o masculino que apontamos no Sagrado Feminino, se seguirmos profundamente seus argumentos, em especial os contidos em obras em que ele dialoga com princípios alquímicos, como O Livro vermelho (2002) e Mysterium Coniuctionis (2012), e na obra Arquétipos e o Inconsciente Coletivo (2000), reconheceremos que Jung postula, de fato, uma psique híbrida para todxs, em que animus e anima estariam presentes como energias e representações do masculino e do feminino sem um conteúdo definido em todos os seres humanos, atuando de forma complementar no dinamismo da psique.

Com a proposta de Jung, de integração, união, fusão, conciliação de opostos (coincidentia oppositorium), baseada em uma dimensão mítica de busca pela totalidade e integralidade perdidas, os conceitos de animus e anima ganham uma perspectiva que foge do dualismo binário e caminha para a androginia.

Nesse contexto, Jung afirma:

Na medida em que a cultura se desenvolve, o ser originário bissexual torna-se símbolo da unidade da personalidade [...] [na qual] o conflito entre opostos se apazigua. Neste caminho, o ser originário torna-se a meta distante de auto realização do ser humano, sendo que desde o início já fora uma projeção da totalidade inconsciente (Carl JUNG, 2000, p. 177). 
Esse caminho integrador coloca os conceitos de animus e anima como polaridades energéticas complementares na psique que teriam, como finalidade primordial, a produção de uma síntese simbólica e psicológica, conhecida como Coniunctio, união alquímica, ou casamento sagrado. A sígizia ou par de opostos é vivenciada com base na ideia de integralidade.

Tal perspectiva é baseada no mito da totalidade perdida e envolve a metáfora do nascimento da consciência. "O alargamento da consciência é, inicialmente, sublevação e escuridão, então se segue uma expansão do homem em direção ao homem total" (Carl JUNG, 2002, p. 209). Edinger, trabalhando a perspectiva de união dos opostos afirmou que "eu penso que no futuro a maior medida do valor de um indivíduo será a de que ele tem consciência de sua capacidade de ser portador dos opostos" (Edward EDINGER, 2008, p. 31). As polaridades trazem, como potência, a chance de acessar a outra ponta da experiência, de modo a produzir aprendizados, sínteses e arranjos pessoais de consciência.

Nesse sentido, a ideia de opostos complementares carrega algumas questões. A primeira é a do mito da totalidade perdida, que está na base do trabalho com as polaridades energéticas como animus e anima, sendo que seu destino final é uma consciência híbrida que transcende as partes. A segunda questão é que a psique andrógina tem como base mítica uma natureza de opostos que se complementam. Samuels aponta: "a visão de Jung era a de que o homem e a mulher seriam incompletos um sem o outro; a heterossexualidade seria, dessa forma, uma determinação" (Andrew SAMUELS, 1992, p. 133).

Esse é um ponto importante de nossa comunicação. Entendemos, de modo distinto de Samuels, que a visão de Jung fornece bases para um arranjo plural da energia sexual da psique. Isso porque trabalha em uma compreensão mítica e não literal. Mesmo tendo Jung em alguns momentos cometido o equívoco de personificar a anima e o animus, sua teoria dos opostos tem uma base conceitual mítica e alquímica e é desse modo que deve ser considerada. A personificação não deve ser tomada como características inerentes ou grudadas no arquétipo, mas sim deve ser observada de modo a reconhecer a identificação da psique com determinado aspecto do arquétipo, produzindo um trabalho 
curador, criador e integrativo, como ocorre na abordagem da imagem na Psicologia Arquetípica. Conforme apontam Roberto De Sá e Tatiana Deola (2019, p. 13), de maneira a condensar a comprensão:

[...] sendo feminino e masculino, homem e mulher compreendidos de forma não personificada, mas apenas como diferentes, a noção de bissexualidade universal 7 pode passar de algo indiferenciado, polimórfico ou polivalente para uma noção da humanidade que tem acesso a todas as possibilidades relacionadas a papéis de sexo ou gênero.

Se considerarmos a perspectiva mitológica, Ana Lia Aufranc (2018, p. 42) indica que "a maioria dos deuses cosmogônicos tem uma natureza bissexual" e que "na mitologia grega, a androginia, assim como a mudança de sexo, é comum”. Ela aponta as diferenças entre os mitos do Hermafrodito e dos seres andróginos. O primeiro representa uma história de fusão, simbiose e esterilidade, já o mito dos andróginos remete à separação de um estado que era originalmente unido.

Hermafrodito, filho de Hermes e Afrodite, era um jovem belíssimo. A ninfa Sálmacis, ao vê-lo banhando-se na sua fonte, apaixonada, o enlaçou fortemente e pediu aos deuses que jamais a separassem dele. Suas súplicas foram atendidas e os dois corpos foram fundidos em um só. Hermafrodito, ao perceber o que havia ocorrido, implora aos pais, no que é atendido, que todo aquele que se banhasse nas águas límpidas da fonte de Sálmacis ficasse impotente. O Hermafrodito estaria assim associado à simbiose e à esterilidade, representaria um movimento regressivo dos dois diferenciado para o um.

$[\ldots]$

Já os andróginos, em o Banquete de Platão, de acordo com Aristófanes, eram seres esféricos que incluíam os dois sexos e que foram se tornando audaciosos, a ponto de ameaçar os deuses com suas tentativas de escalar o Olimpo. Zeus, face ao perigo, resolveu cortar o andrógino em duas partes e encarregou Apolo de curar suas feridas e virar seus rostos para o lado em que a separação havia sido feita. Assim eles poderiam contemplar a marca dos cortes, o umbigo e,

7 A noção de bissexualidade universal está presente em Jung (2002; 2009) e é utilizada para se referir à constituição andrógina da qual a consciência advém e para a qual caminha em relação às energias femininas e masculinas. Tem relação com o mito dos seres andróginos.

Mandrágora, v.25, n. 2, 2019, p. 127-151 
com isso, se tornariam mais humildes. Cada metade tem procurado, desde então, a outra contrária em um desejo intenso de se "re-unir" e foi assim que teve origem o amor. (Ana Lia AUFRANC, 2018, p. 42).

Metades que querem se encontrar parece relacionar-se com a metáfora da tampa na panela, criticada como um mecanismo do amor romântico em que as partes não seriam inteiras em si, necessitando que outrxs a complementem. No entanto, lembramos que a perspectiva mítica comporta outras leituras. Comparando as imagens do Hermafrodito e dos seres andróginos, compreendemos porque recorremos à defesa da psique andrógina, já que Jung fala que a meta da psique é a união das polaridades, e que tal processo está na base do nascimento da consciência, que retorna ao seu estado de totalidade e integração originais. A ideia é que a polaridade contém a possibilidade de acessar o todo, pelo espelhamento com o outro polo. O movimento do mito é de estado integrado original, separação e desejo de re-união. Nesse sentido, é um movimento de ciclos e retornos entre separação e totalidade. Acompanhando essa imagem, a pesquisadora Maria Lucia Faury (1995) propõe que a androginia psíquica fala de um ideal mitológico ligado a um movimento em espiral.

A partir dos pontos observados, verificamos que a concepção junguiana acerca de gênero é mítica e não literal, o que quer dizer que toda personificação de animus e anima, mesmo as realizadas por Jung, são tentativas de mostrar as facetas que são parte de um todo indiferenciado. Se nos focarmos na meta da totalidade, o binarismo torna-se circunstancial, didático, e não uma caraterística essencialista do feminino e do masculino, como alguns grupos do Sagrado Feminino têm incorporado. As concepções de animus e anima não deveriam ser traduzidas como o masculino é y e o feminino é $x$, pois não foi desse modo que Jung se pronunciou. A popularização da teoria junguiana e sua utilização no campo esotérico trouxe uma prática de simplificação de alguns de seus conceitos. E esta simplificação deu lugar ao reducionismo / essencialismo que atrela características específicas (conteúdo) ao arquétipo do masculino e do feminino (forma).

Desse modo, masculino e feminino não seriam representações diretas e literais de como ser homem e como ser mulher ou, ainda, de 
como devem ser homens e mulheres, mas sim, princípios energéticos com potencial de tornarem-se algo além de si. Com isso, Jung estava desvinculando o binarismo de uma característica que poderia estar atrelada à essência de gênero, ligando-o a condições passageiras de um estágio de identificação da psique em relação ao tema. Em O Livro Vermelho, Jung (2009, p. 203) questiona: "vós procurais o feminino na mulher e o masculino no homem. E assim há sempre apenas homens e mulheres. Mas onde estão as pessoas? (...) a pessoa é masculina e feminina, não é só homem ou só mulher. De tua alma não sabes dizer de que gênero ela é".

Claramente, essa passagem contém uma semente subversiva importante, que libera a psique humana de não ser previamente determinada a um destino de gênero. A Psicologia Junguiana abre possibilidades para a compreensão de uma psique fluida, com potencial para arranjos múltiplos e não-binários de gênero.

Já em relação à sexualidade, o debate torna-se menos claro que aquele sobre gênero. Jung coloca:

O mais difícil é estar além do sexual e ficar dentro do humano. Se te elevas acima do sexual, com a ajuda de uma proposição geral, tu mesmo te tornas aquela proposição e ultrapassas o humano. Ficarás portanto seco, duro e inumano. (...) Quando atuas a partir do humano, atuas a partir da respectiva situação, sem princípio geral (...) Pessoas dessa espécie não estão além da sexualidade devido a um princípio geral, mas devido à sua imaginação na qual se perderam. Tornaram-se sua própria imaginação e arbitrariamente, para seu próprio prejuízo. Faz-lhes falta lembrar-se do sexual a fim de que acordem de seus sonhos pra realidade. (Carl JUNG, 2009, p. 206)

Essa difícil tarefa de vivenciar a sexualidade dentro de cada situação humana pode levar a categorizações sexuais que são na, verdade, projeções, manifestações, representações e identificações de uma psique atuando em busca da consciência. A vivência andrógina não é estéril, inclui a sexualidade, mas coloca o humano diante de muitas possibilidades de vivenciá-la sem perder de vista a unicidade. Estar além dos papéis de sexo e gênero não significa não ter papéis (Roberto DE SÁ e Tatiana DEOLA, 2019, p. 20). 
A pesquisadora Sonia Lyra assim se pronuncia a esse respeito:

Quando se pensa nesse par de opostos anima/animus, é comum emergir a questão referente à homossexualidade e à bissexualidade, ou, ainda, à transsexualidade. (...) pode-se dizer que os arquétipos anima e animus independem completamente da orientação sexual de homens e mulheres. (Sonia LYRA, 2012, p. 58).

Após essas reflexões, gostaríamos de aproximar a perspectiva do andrógino de Jung à perspectiva do ciborgue da feminista Donna Haraway (2013). Haraway questiona as noções de natureza e cultura na medida em que oferece a metáfora do ciborgue como fruto das construções híbridas que se tem realizado entre humanos e máquinas, símbolo de fronteiras borradas. O ciborgue aparece como possibilidade identitária híbrida, fluida, que quebra dicotomias entre natureza e cultura, ser humano e máquina, ser humano e outros animais, feminino e masculino, corpo e mente. A metáfora do ciborgue é importante em nosso debate porque o ciborgue seria uma transposição do humano, na medida em que oferece possibilidades que a humanidade não atinge com as limitações inerentes ao seu corpo original.

Por esse caráter híbrido, o ciborgue pode ser concebido como um transhumano. $\mathrm{O}$ andrógino também. A imagem do transhumano serve ao andrógino mítico, que se apresenta como uma possibilidade de superação das polaridades, um vir a ser que está embrionário nas possibilidades da consciência de cada ser humano. No entanto, vejamos que entre o ciborgue e o andrógino há diferenças conceituais significativas.

O ciborgue de Haraway é uma figura sem território, definida não por características que lhe são próprias, mas pela pluralidade e multiplicidade de possibilidades e arranjos. Não apela à natureza para existir, constroi-se e recria-se constantemente. Uma frase de Haraway chama atenção para a conexão que gostaríamos de estabelecer: "Os ciborgues não são reverentes, não recordam do cosmo, desconfiam do holismo, mas necessitam conectar" (Donna HARAWAY, 2013, p. 256).

E de que conexão estaria falando Donna Haraway, já que expressamente não se trata de conexão religiosa ou conexão com alguma entidade espiritual? Estaria Haraway se refirindo a conexões com humanxs 
de todos os tipos? Ela propõe que a constituição do nós ocorre através do "des-membramento e des-locamento de nossos nomes e corpos" (Donna HARAWAY, 1993, p.279), fazendo referência, novamente, a esse não-lugar do ciborgue, mas também a esse lugar intermediário, que se constrói na interface.

O ciborgue de Haraway remete-se à simbiose entre orgânico e inorgânico. Dolores Galindo, assim, resume a ideia: "Os ciborgues têm como característica a heterogeneidade constitutiva onde as entidades que o compõem só ganham sentido interativamente" (Dolores GALINDO, 2003, p. 4).

Há que pensar que o ciborgue de Haraway não pode ser desmembrado em suas partes, e esta é uma diferença importante para o pensamento de Jung. O ciborgue não é composto de partes inteiras a que podemos nomear, como animus e anima, por exemplo, no caso da psique andrógina. A psique andrógina é uma meta e um ponto de partida da consciência, mas suas manifestações se dão por meio das partes. No caso do ciborgue, as partes que o compõem não representam algo em si, ou etapas de um processo. Só se nomeia o todo e a sua existência se dá pelo todo híbrido.

Finalmente, nesse diálogo, é preciso resgatar as diferenças de pressupostos e perceber os pontos de contato. Além dessa diferença sobre as partes constitutivas que acabamos de apontar, Jung parte de uma narrativa mítica, na qual a androginia é um ideal possível, mas distante, como meta. Haraway parte de uma concepção de arranjos da construção de subjetividades observáveis na vida, e, portanto, mais concretos. O ponto em que as concepções se encontram parece ser a perspectiva de transposição do humano, indo além de limitações que seriam associadas ao corpo ou às noções de masculino e feminino e promovendo uma síntese híbrida que amplia as possibilidades de vivências e consciências.

\section{CONSIDERAÇÕES FINAIS}

Considerar a artificialidade do pensamento binário, rígido e mutuamente excludente das dicotomias entre masculino e feminino e formular propostas conciliatórias tem sido um esforço de teóricxs ligadxs à História da Ciência recente, como o trabalho de muitas epistemólogas 
feministas, dentre as quais podemos citar Londa Schienbinger (2000), Donna Haraway (2013), Judith Butler (2001; 2003), Diana Maffía (2008), entre outras. Nesse sentido, mesmo considerando que Jung viveu em outra época e que seu pensamento tem sido utilizado para reforçar os binarismos, esperamos ter demonstrado, nesse artigo, que é possível uma conciliação entre os parâmetros da Psicologia Junguiana e os Estudos de Gênero, se bem observados alguns princípios: 1) tratar arquétipo como uma forma não definida, aberta em termos de conteúdos e características; 2) considerar os conceitos de animus e anima como representações dinâmicas que têm por finalidade a composição híbrida e andrógina da psique; 3) tratar as personificações de animus e anima como facetas ou imagens com as quais a psique está identificada no momento, que podem estar estagnando o fluxo energético e devem ser aprofundadas de modo a restabelecer o equilíbrio psíquico; 4) considerar que a teoria de pares complementares, como animus e anima, podem ser tratados, não como opostos, mas como energias diferentes - conforme a proposta de Samuels (1992) - desfazendo a noção de falta, dependência e simbiose na perspectiva de união e fusão; 5) considerar que é possível estabelecer diálogos entre as metáforas do ciborgue e da psique andrógina, na compreensão da transposição de limites humanos e na construção de novos arranjos, resguardando, no entanto, as diferenças conceituais relativas à constituição das partes (que podem ser nomeadas no caso da Psicologia Analítica e no caso do ciborgue, não), e ao universo a que cada termo se reporta (mítico, no caso de Jung e, no caso de Haraway, ligado às lutas de gênero).

Um mérito da teoria de Jung está na reconciliação entre conhecimentos científicos e não científicos na busca por explicações amplas e profundas do funcionamento psíquico humano, resgatando saberes tradicionais, mitológicos e que operam em lógicas muitas vezes excluídas do debate acadêmico. Se houver um manejo mais criterioso de tais conceitos, tendem a ganhar epistemologicamente ambos os lados do debate.

É importante lembrar que Jung viveu em um tempo em que as reivindicações de direitos e políticas públicas de gênero ainda se debruçavam sobre o direito ao voto das mulheres em muitos países, em que a patologização das sexualidades e identidades de gênero não 
convencionais ainda era uma realidade potente, no qual ainda não se formulava entre muitas sociedades a possibilidade civil de casamento entre pessoas do mesmo sexo ou a alteração oficial e pública da identidade de gênero. Não existia ainda a Teoria Queer (proposta inicialmente por Teresa de Laurentis e muito propagada por Judith Butler e Paul / Beatriz Preciado, dentre outrxs autorxs) e toda esta corrente que brada por igualdade e justiça de gênero, particularmente quente hoje em dia e advinda das ondas do feminismo.

De maneira pouco convencional e quebrando paradigmas da ciência da qual era herdeiro, Jung abriu caminhos para pensarmos uma psique andrógina, colocando os opostos como estados intermediários para se chegar à consciência. "Se ao menos pudesse surgir uma consciência universal de que todas as divisões e todas as cisões são devidas à divisão dos opostos na psique, então nós saberíamos por onde começar" (Carl JUNG, 2002, p. 575). Para ele, a psique andrógina é a base e, ao mesmo tempo, a meta da consciência, o que libera as vivências de gênero e sexualidade para existirem de diferentes maneiras. Na teoria junguiana e arquetípica, as facetas com as quais animus e anima se identificam durante o processo de individuação ou desenvolvimento da consciência não representam o feminino e o masculino em si, mas etapas do processo, imagens, facetas do grande caleidoscópio que é a consciência.

Em termos de lutas de gênero, não se pode pensar a emancipação feminina hoje sem a formação de redes, que incluem as mais diferentes concepções da luta feminina e feminista. Nesse caso, a Psicologia Junguiana e sua linha arquetípica podem se recolocar no debate público sobre gênero, trazendo uma revisão de práticas que se apoiam em seus conceitos, como é o caso dos Círculos Sagrados de Mulheres - que podem se reinventar através do acolhimento de mulheres (e quem sabe, de pessoas não-binárias) que se identifiquem como tal mesmo que não possuam o que é biologicamente considerado como sendo de mulher.

Concluindo este texto, deixamos aqui a pergunta: é possível que o feminino que se pretende sacralizado encontre-se com a perspectiva feminista de descontrução dos estereótipos de gênero? Podemos pensar em um Sagrado não-binário, a partir da proposta da psique andrógina? 


\section{REFERÊNCIAS}

AUFRANC, Ana Lia B. Expressões da sexualidade: um olhar junguiano. Revista Junguiana, São Paulo , v. 36, n. 1, 2018, p. 37-48.

BARCELLOS, Gustavo. Introdução: A Anima 30 anos pós-Jung. In: HILLMAN, James. Psicologia Arquetípica. São Paulo: Cultrix, 1983, p. 7-18.

BOURDIEU, Pierre. A economia das trocas linguísticas. São Paulo: EDUSP, 1996.

BUTLER, Judith. Corpos que pesam: sobre os limites discursivos do sexo. In: LOURO, Guacira Lopes (Org.). O corpo educado. Belo Horizonte: Autêntica, 2001, p. 151-172.

BUTLER, Judith. Problemas de gênero: feminismo e subversão da identidade. Rio de Janeiro: Civilização Brasileira, 2003.

CORDOVIL, Daniela. O poder feminino nas práticas da Wicca: uma análise dos "Círculos de Mulheres". Estudos Feministas. v. 23, n. 2, mai.-ago., 2015, p. 431-449.

DE SÁ, Roberto Novaes; DEOLA, Tatiana. Reflexões sobre a questão da personificação na teoria da contra-sexualidade de Jung e a androginia psíquica na contemporaneidade.

CES REVISTA, v. 33, n. 1, 2019.

EDINGER, Edward. O mistério da Coniunctio: imagem alquímica da individuação. São Paulo: Paulus, 2008.

FAURY, Mára Lucia. Fronteiras do Masculino e do Feminino ou A Androginia como Expressão. Cadernos Pagu, n. 5, 1995, p. 164-178. Acesso em: 15 mar. 2017.

GALINDO, Dolores Cristina. Sobre os ciborgues como figuras de borda. Athenea Digital, Revista de Pensamiento e Investigación Digital, n. 4, 2003.

HARAWAY, Donna. "Manifesto Ciborgue". In: TADEU, Tomaz (Org.). Antropologia do Ciborgue: As vertigens do pós-humano. Belo Horizonte: Autêntica Editora, 2013.

HILLMAN, James. Anima: anatomia de uma noção personificada. São Paulo: Cultrix, 1985. HILLMAN, James. Psicologia Arquetípica. São Paulo: Cultrix, 1983.

JUNG, Carl Gustav. O livro vermelho. Petrópolis: Vozes, 2009.

JUNG, Carl Gustav. Mysterium coniunctionis: investigación sobre la separación y la unión de los opuestos anímicos en la alquimia. Madrid: Trotta, 2002.

JUNG, Carl Gustav. Arquétipos e o Inconsciente Coletivo. São Paulo: Vozes, 2000.

LEMOS, Carolina Teles. Religião e Patriarcado: elementos estruturantes das concepções e das relações de gênero. Revista Caminhos. Goiânia, v. 11, n. 2, jul.-dez., 2013, p. 201-217. LYRA, Sonia. Arte e gênero androgenidade: A Dialética do Apogeu. Rev. Pistis \& Praxis, Teologia e Pastoral, Curitiba, v. 4, n. 1, jan.-jul. 2012, p. 51-61.

MAFFÍA, Diana. Contra las dicotomias: feminismo y epistemologia crítica. Instituto Interdisciplinario de Estudios de Género, Universidad de Buenos Aries, 2008. 
MARANHÃO Fo, Eduardo Meinberg de Albuquerque. "A travesti morreu, mas carrego ela no caixão" e outras histórias vivas: conversão, transfobia religiosa e morte. Revista Brasileira de História das Religiões, ANPUH, v. 10, n. 9, 2017, p. 165-216.

MARANHÃO $\mathrm{F}^{\circ}$, Eduardo Meinberg de Albuquerque. (Re/des)conectando gênero e religião. Peregrinações e conversões trans* e ex-trans* em narrativas orais e do Facebook. Tese (Doutorado). Programa de Pós-Graduação em História Social. Universidade de São Paulo. São Paulo, 2015.

MARANHÃO $\mathrm{F}^{\circ}$, Eduardo Meinberg de Albuquerque. Sai desse corpo que esse caminho não te pertence! Pessoas trans* e ex-trans* em (re/des)caminhos de gênero, corpo e alma. Revista Brasileira de História das Religiões, ANPUH, Ano VIII, n. 24, 2016, p. 197-219.

MARANHÃO Fo, Eduardo Meinberg de Albuquerque. "Um tapa na cara pra quem diz que cura gay não existe": A ideologia de gênesis em Cleycianne, Lady Gaga e Marco Feliciano. Religare, v. 15, n. 2, 2018, p. 612-651.

MARANHÃO $F^{\circ}$, Eduardo Meinberg de Albuquerque; FRANCO, Clarissa de. "Menino veste azul e menina, rosa": Educação Domiciliar e as ideologias de gênero e gênesis de Damares Alves, a "ministra terrivelmente cristã" dos Direitos Humanos. Revista Brasileira de História das Religiões, ANPUH, Ano XII, n. 35, 2019, p. $297-337$.

ROSADO-NUNES, Maria José Fontelas. A “ideologia de gênero" na discussão do PNE: a intervenção da hierarquia católica. Revista Horizonte, Belo Horizonte, v. 13, n. 39, jul.-set., 2015, p. 1237-1260.

SAMUELS, Andrew. A Psique Plural: Personalidade, Moralidade e o Pai. Rio de Janeiro: Imago, 1992.

SCHIEBINGER, Londa. Has Feminism Changed Science? Signs, v. 25, n. 4, 2000, p. 1171-1175. YOUNG-EISENDRATH, Polly; DAWSON, Terense. Manual de Cambridge para Estudos Junguianos. Porto Alegre: Artmed Editora, 2002.

Submetido em: 17-10-2019

Aceito em: 19-11-2019 